\title{
Averting the Legacy of Kidney Disease-Focus on Childhood
}

\author{
"For in every adult there dwells the child that was, and in every child there lies the adult that will be." \\ - John Connolly, The Book of Lost Things \\ Julie R Ingelfinger, Kamyar Kalantar-Zadeh, Franz Schaefer \\ on behalf of the World Kidney Day Steering Committee*
}

\section{ABSTRACT}

World Kidney Day 2016 focuses on kidney disease in childhood and the antecedents of adult kidney disease that can begin in earliest childhood. Chronic kidney disease (CKD) in childhood differs from that in adults, as the largest diagnostic group among children includes congenital anomalies and inherited disorders, with glomerulopathies and kidney disease in the setting of diabetes being relatively uncommon. In addition, many children with acute kidney injury will ultimately develop sequelae that may lead to hypertension and CKD in later childhood or in adult life. Children born early or who are small-for date newborns have relatively increased risk for the development of CKD later in life. Persons with a high-risk birth and early childhood history should be watched closely in order to help detect early signs of kidney disease in time to provide effective prevention or treatment. Successful therapy is feasible for advanced CKD in childhood; there is evidence that children fare better than adults, if they receive kidney replacement therapy including dialysis and transplantation, while only a minority of children may require this ultimate intervention Because there are disparities in access to care, effort is needed so that those children with kidney disease, wherever they live, may be treated effectively, irrespective of their geographic or economic circumstances. Our hope is that World Kidney Day will inform the general public, policy makers and caregivers about the needs and possibilities surrounding kidney disease in childhood.

\section{Introduction and Overview}

The 11th World Kidney Day will be celebrated on March 10, 2016, around the globe. This annual event, sponsored jointly by the International Society of Nephrology (ISN) and the International Federation of Kidney Foundations (IFKF), has become a highly successful effort to inform the general public and policymakers about the importance and ramifications of kidney disease. In 2016, World Kidney Day will be dedicated to kidney disease in childhood and the antecedents of adult kidney disease, which can begin in earliest childhood.

Children who endure acute kidney injury (AKI) from a wide variety of conditions may have long-term sequelae that can lead to chronic kidney disease (CKD) many years later $(1,2,3,4)$. Further, CKD in childhood, much of it congenital, and complications from the many non-renal diseases that can affect the kidneys secondarily, not only lead to substantial morbidity and mortality during childhood but also result in medical issues beyond childhood. Indeed, childhood deaths from a long list of communicable diseases are inextricably linked to kidney involvement. For example, children who succumb to cholera and other diarrheal infections often die, not from the infection, but because of AKI induced by volume depletion and shock. In addition, a substantial body of data indicates that hypertension, proteinuria and CKD in adulthood have childhood antecedents-from as early as in utero and perinatal life (see Table 1 for definitions of childhood). World Kidney Day 2016 aims to heighten general awareness that much adult renal disease is actually initiated in childhood. Understanding high risk diagnoses and events that occur in childhood have the potential to identify and intervene preemptively in those people at higher risk for CKD during their lifetimes.

Worldwide epidemiologic data on the spectrum of both CKD and AKI in children are currently limited, though increasing in scope. The prevalence of CKD in childhood is rare-and has been variously reported at 15-74.7 per million children (3). Such variation is likely because data on CKD are influenced by regional and cultural factors, as well as

\section{Address for Correspondence}

World Kidney Day, International Society of Nephrology, in collaboration with International Federation of Kidney Foundation Rues de Fabriques $1 B$, 1000, Brussels, Belgium E-mail: myriam@worldkidneyday.org

*Members of the World Kidney Day Steering Committee are: Philip Kam Tao Li, Guillermo Garcia-Garcia, William G. Couser, Timur Erk, Julie R Ingelfinger, Kamyar Kalantar-Zadeh, 
World Kidney Day 2016

\begin{tabular}{|l|l|}
\hline Table 1. Definitions of stages of early life & 22 completed weeks of gestation to day $\mathbf{7}$ of postnatal life \\
\hline Perinatal Period- & Birth to day 28 of postnatal life \\
\hline Neonatal Period- & Birth to 1 year of age \\
\hline Infancy & 1 year of age to 10 years of age \\
\hline Childhood & 10 years of age to 19 years of age \\
\hline Adolescence & $\begin{array}{l}\text { Notes: } \\
\text { The data in this table are as defined by the World Health Organization. The perinatal period is defined as } 22 \text { completed weeks of gestation to Day } 7 \text { of life; the neonatal period, as up to } \\
28 \text { days of life; infancy as up to one year of age; childhood as year } 1 \text { to } 10 ; \text { and adolescence from } 10 \text { years to age } 19 . \\
\text { There is variation worldwide in how these stages of early life are defined. Some would define "young people" as those age } 24 \text { or less. In the United States, childhood is as a whole } \\
\text { defined as going to age 21. }\end{array}$
\end{tabular}

by the methodology used to generate them. The World Health Organization (WHO) has recently added kidney and urologic disease to mortality information tracked worldwide, and should be a valuable source of such data over timeyet WHO does not post the information by age group (5). Databases such as the North American Pediatric Renal Trials and Collaborative Studies (NAPRTCS) (6) the U.S. Renal Data System (USRDS) (7) and the EDTA registry (8) include data on pediatric ESRD, and some on CKD. Projects such as the ItalKid(9) and Chronic Kidney Disease in Children (CKiD) (10) studies, the Global Burden of Disease Study 2013, as well as registries that now exist in many countries provide important information, and more is required (11).

AKI may lead to CKD, according to selected adult population studies (12). The incidence of AKI among children admitted to an intensive care unit varies widely-from $8 \%$ to $89 \%$ (1). The outcome depends on the available resources. The results from projects such as the AWARE study, a fivenation study of AKI in children are awaited (13). Single center studies, as well as meta-analyses indicate that both AKI and CKD in children account for a minority of CKD worldwide $(2,3)$. However, it is increasingly evident that kidney disease in adulthood often springs from a childhood legacy.

\section{Spectrum of Pediatric Kidney Diseases}

The conditions that account for CKD in childhood, with a predominance of congenital and hereditary disorders, differ substantially from those in adults. To date, mutations in more than 150 genes have been found to alter kidney development or specific glomerular or tubular functions (14). Most of these genetic disorders present during childhood, and many lead to progressive CKD. Congenital anomalies of the kidney and urinary tract (CAKUT) account for the largest category of CKD in children (see Table 2) and include renal hypoplasia/dysplasia and obstructive uropathy. Important subgroups among the renal dysplasias are the cystic kidney diseases, which originate from genetic defects of the tubuloepithelial cells' primary cilia. Many pediatric glomerulopathies are caused by genetic or acquired defects

\begin{tabular}{|l|l|l|l|}
\hline \multicolumn{4}{|l|}{ Table 2. Etiology of chronic kidney disease in children } \\
\hline CKD & & ESRD & \\
\hline Etiology & Percentage (Range) & Etiology & Percentage (Range) \\
\hline CAKUT & $48-59 \%$ & CAKUT & $34-43 \%$ \\
\hline GN & $5-14 \%$ & GN & $15-29 \%$ \\
\hline HN & $10-19 \%$ & HN & $12-22 \%$ \\
\hline HUS & $2-6 \%$ & HUS & $2-6 \%$ \\
\hline Cystic & $5-9 \%$ & Cystic & $6-12 \%$ \\
\hline Ischemic & $2-4 \%$ & Ischemic & $2 \%$ \\
\hline $\begin{array}{l}\text { Rare causes include congenital NS, metabolic diseases, cystinosis/Miscellaneous } \\
\text { causes depend on how such entities are classified. } \\
\text { CAKUT: Congenital anomalies of the kidney and urinary tract, GN: Glomerulonephritis, } \\
\text { HN: hereditary nephropathy, HUS: Hemolytic uremic syndrome. } \\
\text { *from Harambat et al. CKD data are from NAPRTCS, the Italian Registry and the } \\
\text { Belgian Registry. ESRD data are from ANZDATA, ESPN/ERA-EDTA, UK Renal Registry } \\
\text { and the Japanese Registry. }\end{array}$
\end{tabular}

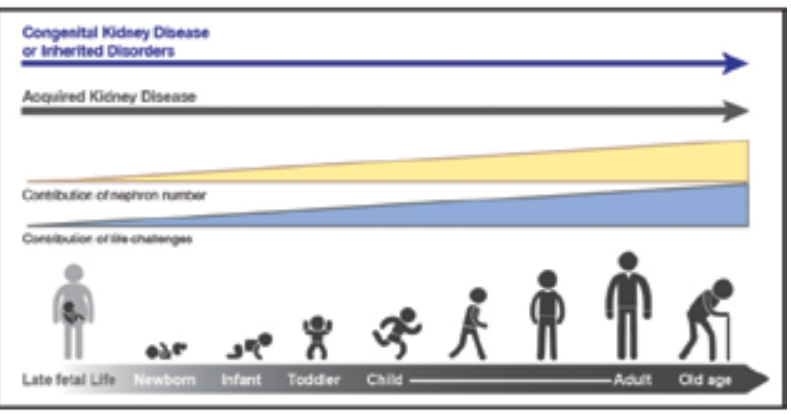

Figure 1. Legend: The types and risks of kidney disease change across the lifecycle. The contribution of nephron number increases over the life cycle, in concert with events that provide direct insults and challenges to kidney health

of the podocytes, the unique cell type lining the glomerular capillaries. Less common but important causes of childhood CKD are inherited metabolic disorders such as hyperoxaluria and cystinosis, and atypical hemolytic uremic syndrome, a thrombotic microangiopathy related to genetic abnormalities of complement, coagulation or metabolic pathways. 
In various classifications it is not clear how to categorize children who have suffered AKI and apparently recovered, or how and whether to include those children who have had perinatal challenges, likely resulting in a relatively low nephron number.

Among children with childhood-onset end-stage renal disease (ESRD) glomerulopathies are slightly more and congenital anomalies less common (Table 2), due to the typically more rapid nephron loss in glomerular disease. However, recent evidence suggests that many patients with milder forms of CAKUT may progress to ESRD during adulthood, peaking in the fourth decade of life (15).

There are national and regional differences in the types and course of both $\mathrm{AKI}$ and CKD during childhood and beyond. Death from kidney disease is higher in developing nations, and national and regional disparities in care and outcome must be addressed. Further, access to care is variable, depending on the region, the country and its infrastructure. By focusing on kidney disease in childhood, cost-effective solutions may be reached, as treating disease early and preemptively may prevent later, more advanced CKD. Expectations depend on the availability of care and management. Treating children, even from infancy, who have $A K I$ and CKD that requires renal replacement therapy can be effective in mitigating the burden of kidney disease in adulthood. Doing so requires resources that focus on the most expeditious and cost-effective ways to deliver acute RRT in childhood.

\section{Congenital Kidney Disease and Developmental Origins of Health and Disease, Renal Endowment and Implications}

In regions where antenatal fetal ultrasounds are routine, many children with urologic abnormalities are identified antenatally, which permits early intervention. However, in much of the world, children with structural abnormalities are not identified until much later, when symptoms develop. While generalized screening for proteinuria, hematuria and urinary tract infections are carried out in some countries and regions, there is a lack of consensus as to its effectiveness. However, there is general agreement that children with antenatal ultrasound studies that indicate possible genitourinary anomalies, children with a family history of kidney disease, and children with signs such as failure to thrive or a history of urinary tract infection, voiding dysfunction or an abnormal appearing urine should be examined. Initial screening would include a focused physical examination and a urine dipstick, formal urinalysis and a basic chemistry panel, followed by a more focused evaluation if indicated.

Depending on the diagnosis, definitive therapy may be indicated. However, the evidence that therapy will slow progression of CKD in childhood remains limited. Angiotensin converting enzyme inhibitors, angiotensin receptor blockers, antioxidants and, possibly, dietary changes may be indicated, depending on the diagnosis. However, dietary changes need to permit adequate growth and development. The ESCAPE trial provided evidence that strict blood pressure control retards progression of CKD in children irrespective of the type of underlying kidney disease (16).

Some very young children may require renal replacement therapy in early infancy. Recent data pooled from registries world wide indicate good survival, even when dialysis is required from neonatal age $(2,17)$. Kidney transplantation, the preferred renal replacement therapy in children, is generally suitable after 12 months of age, with excellent patient and allograft survival, growth and development.

Evidence is accumulating that childhood-onset CKD leads to accelerated cardiovascular morbidity and shortened life expectancy. Ongoing large prospective studies such as the (Cardiovascular Comorbidity in Children with CKD (4C) Study are expected to inform about the causes and consequences of early cardiovascular disease in children with CKD (18).

In addition to those children with congenital kidney disease, it is now known that perinatal events may affect future health in the absence of evident kidney disease in early life (19). Premature infants appear to be particularly at risk for kidney disease long after they are born, based both on observational cohort studies, as well as on case reports. Increasingly premature infants survive, including many born well before nephrogenesis is complete (20). The limited data available indicate that in the process of neonatal ICU care, such babies receive many nephrotoxins, and that those dying prior to discharge from the nursery have fewer and larger glomeruli (21). Additionally, those surviving have evidence of renal impairment that may be subtle (22). Even more concerning, abundant epidemiologic data indicate that persons born at term but with relatively low birth weights may be at high risk for hypertension, albuminuria and CKD in later life (23). When direct measurements are pursued, such persons, as adults, may have fewer nephrons, thus a low cardiorenal endowment.

In focusing on children for World Kidney Day, we would note that it is key to follow kidney function and blood pressure throughout life in those persons born early or small-for-dates. By doing so, and avoiding nephrotoxic medications throughout life, it may be possible to avert CKD in many people.

\section{Resources and Therapeutics for Children-Differences from Therapeutics in Adults}

Disparities exist in the availability of resources to treat $\mathrm{AKI}$ in children and young people; consequently, too many 
children and young adults in developing nations succumb if AKI occurs. To address the problem the ISN has initiated the Saving Young Lives Project, which aims both to prevent AKI with prompt treatment of infection and/or delivery of appropriate fluid and electrolyte therapy, and to treat AKI when it occurs. This ongoing project in SubSaharan Africa and South East Asia, in which four kidney foundations participate equally (IPNA, ISN, ISPD and SKCF), * focuses on establishing and maintaining centers for the care of $A K I$, including the provision of acute peritoneal dialysis. It links with the ISN's 0 by 25 project, which calls on members to ensure by 2025 that nobody dies from preventable and acute kidney injury.

In view of the preponderance of congenital and hereditary disorders, therapeutic resources for children with CKD have historically been limited to a few immunological conditions. Very recently, progress in drug development in concert with advances in genetic knowledge and diagnostic capabilities has begun to overcome the long-standing 'therapeutic nihilism' in pediatric kidney disease. Atypical HUS, long considered ominous, with a high likelihood of progression to ESRD and post-transplantation recurrence, has turned into a treatable condition-with the advent of a monoclonal antibody that specifically blocks C5 activation (24). Another example is the use of vasopressin receptor antagonists to retard cyst growth and preserve kidney function in polycystic kidney disease (25). First proven efficacious in adults with autosomal dominant polycystic kidney disease, therapy with vaptans holds promise also for the recessive form of the disease, which presents and often progresses to ESRD during childhood.

However, patient benefit from pharmacological research breakthroughs is jeopardized on a global scale by the enormous cost of some of the new therapeutic agents. The quest for affordable innovative therapies for rare diseases will be a key issue in pediatric nephrology in the years to come.

The identification of children likely to benefit from novel therapeutic approaches will be greatly facilitated by the development of clinical registries that inform about the natural disease course, including genotype-phenotype correlations. Apart from disease-specific databases, there is also a need for treatment-specific registries. These are particularly relevant in areas where clinical trials are difficult to perform due to small patient numbers and lacking industry interest, as well as for therapies in need of global development or improvement. For instance, there is currently a large international gradient in the penetration and performance of pediatric dialysis and transplantation. Whereas pediatric patient and technique survival rates are excellent and even superior to those of adults in many industrialized countries, it is estimated that almost half of the world's childhood population is not offered chronic renal replacement therapy (RRT) at all. Providing access to RRT for all children will be a tremendous future challenge. To obtain reliable information on the demographics and outcomes of pediatric RRT, the International Pediatric Nephrology Association (IPNA) is about to launch a global populationbased registry. If successful, the IPNA RRT registry might become a role model for global data collection.

\section{Transition from Pediatric to Adult Care}

Transition of care for adolescents with kidney disease into an adult setting is critical both for patients and their caregivers. Non-adherence is a too-frequent hallmark of transition from pediatric to adult care for young patients with chronic disease states $(26,27,28)$. Hence, considered steps combined with systematically defined procedures supported by validated pathways and credible guidelines must be in place to ensure successful outcomes.

In the process of change from pediatric to adult care "transition," which should occur gradually, must be distinguished from "transfer," which is often an abrupt and mechanistic change in provider setting. Introducing the concept of transition should be preemptive, starting months to years prior to the targeted time, as children move into adolescence and adulthood. The ultimate goal is to foster a strong relationship and individualized plan in the new setting that allows the patient to feel comfortable enough to report non-adherence and other lapses in care.

A transition plan must recognize that the emotional maturity of children with kidney disease may differ widely. Assessment of the caregiver and the family structure as well as cultural, social, and financial factors at the time of transition are key, including a realistic assessment of caregiver burden (4). The appropriate timing and format of transition may vary widely among different patients and in different settings; therefore, a flexible process without a set date and even without a delineated format may be preferred.

Importantly, transition may need to be slowed, paused or even reversed temporarily during crises such as disease flares or progression, or if family or societal instability occurs. A recent joint consensus statement by the International Society of Nephrology (ISN) and International Pediatric Nephrology Association (IPNA) proposed steps consistent with the points just outlined, aiming to enhance the transition of care in kidney disease in clinical practice $(29,30)$.

\section{Call for Generating further Information and Action}

Given vulnerabilities of children with kidney disease including impact on growth and development and future life as an adult, and given the much greater proportion of 
children in developing nations facing resource constraints educating everyone involved is imperative in order to realign communications and actions $(31,32)$. These efforts should foster regional and international collaborations and exchange of ideas between local kidney foundations, professional societies, other not-for-profit organisations, and states and governments, so as to help empower all stakeholders to improve the health, well-being and quality of life of children with kidney diseases and to ensure their longevity into adulthood.

Until recently, however, the WHO consensus statementon non-communicable diseases (NCD) included cardiovascular disease, cancer, diabetes and chronic respiratory disease, but not kidney disease $(33,34)$. Fortunately, due, in part, to a global campaign led by the ISN, the Political Declaration on NCDs from the United Nations Summit in 2011 mentioned kidney disease under Item 19 (35).

Increasing education and awareness about renal diseases in general and kidney disease in childhood in particular is consistent with the objectives of the WHO to reduce mortality from NCD with a 10 year target population level initiatives focusing on changes in life style (including tobacco use reduction, salt intake control, dietary energy control, and alcohol intake reduction) and effective interventions (including blood pressure, cholesterol and glycemic control). Heightened efforts are needed to realign and expand these multidisciplinary collaborations with more effective focus on early detection and management of kidney disease in children. Whereas the issues related to kidney disease may be overshadowed by other NCDs with apparently larger public health implications such as diabetes, cancer, and cardiovascular diseases, our efforts should also increase education and awareness on such overlapping conditions as cardiorenal connections, the global nature of the CKD and ESRD as major NCDs, and the role of kidney disease as the multiplier disease and confounder for other NCDs. White papers including consensus articles and blueprint reviews by world class experts can serve to enhance these goals (36).

Footnote: *The four partners are (in alphabetical order): IPNA (International Pediatric Nephrology Association), ISN (International Society of Nephrology), ISPD (International Society for Peritoneal Dialysis), SKCF (Sustainable Kidney Care Foundation).

\section{Comprehensive Style of the References (with PMID and PMCID)}

1. Goldstein SL. Acute kidney injury in children and its potential consequences in adulthood. Blood Purif 2012;33:131-137. Epub 2012 Jan 20

2. Harambat J, van Stralen KJ, Kim JJ, Tizard EJ. Epidemiology of chronic kidney disease in children. Pediatr Nephrol 2012;27:363-373. Epub 2011 Jun 29
3. Warady BA, Chadha V. Chronic kidney disease in children: the global perspective. Pediatr Nephrol 2007;22:1999-2009. Epub 2007 Feb 20

4. Furth SL, Cole SR, Moxey-Mims M, Kaskel F, Mak R, Schwartz G, Wong C, Muñoz A, Warady BA. Design and methods of the Chronic Kidney Disease in Children (CKiD) prospective cohort study. Clin J Am Soc Nephrol 2006;1:1006-1015. Epub 2006 Jul 19

5. Health statistics and information systems: Estimates for 2000-2012. http://www.who.int/healthinfo/global_burden_ disease/estimates/en/index1.html.

6. NAPRTCS Annual Reports https://web.emmes.com/study/ ped/annlrept/annlrept.html.

7. Saran R, Li Y, Robinson B, Ayanian J, Balkrishnan R, BraggGresham J, Chen JT, Cope E, Gipson D, He K, Herman W, Heung M, Hirth RA, Jacobsen SS, Kalantar-Zadeh K, Kovesdy CP, Leichtman AB, Lu Y, Molnar MZ, Morgenstern H, Nallamothu B, O'Hare AM, Pisoni R, Plattner B, Port FK, Rao P, Rhee CM, Schaubel DE, Selewski DT,Shahinian V, Sim JJ, Song P, Streja E, Kurella Tamura M, Tentori F, Eggers PW, Agodoa LY, Abbott KC. US Renal Data System 2014 Annual Data Report: Epidemiology of Kidney Disease in the United States. Am J Kidney Dis 2015;66(Suppl 1):1-305.

8. ESPN/ERA-EDTA Registry, European Registry for Children on Renal Replacement Therapy http://www.espn-reg.org/index. jsp.

9. Ardissino G, Daccò V, Testa $S$, Bonaudo R, Claris-Appiani A, Taioli E, Marra G, Edefonti A, Sereni F; ItalKidProject. Epidemiology of chronic renal failure in children: data from the ItalKid project. Pediatrics 2003;111:382-387.

10. Wong CJ, Moxey-Mims M, Jerry-Fluker J, Warady BA, Furth SL. CKiD (CKD in children) prospective cohort study: a review of current findings. Am J Kidney Dis 2012;60:1002-1011. Epub 2012 Sep 28

11. Global Burden of Disease Study 2013 Collaborators. Global, regional, and national incidence, prevalence, and years lived with disability for 301 acute and chronic diseases and injuries in 188 countries, 1990-2013: a systematic analysis for the Global Burden of Disease Study 2013. Lancet 2015;386:743800. Epub 2015 Jun 7

12. Coca SG, Singanamala S, Parikh CR. Chronic kidney disease after acute kidney injury: a systematic review and metaanalysis. Kidney Int 2012;81:442-448.

13. Basu RK, Kaddourah A, Terrell T, Mottes T, Arnold P, Jacobs J, Andringa J, Goldstein SL; Prospective Pediatric AKI Research Group (ppAKI). Assessment of Worldwide Acute Kidney Injury, Renal Angina and Epidemiology in critically ill children (AWARE): study protocol for a prospective observational study. BMC Nephrol 2015;16:24.

14. Eckardt KU, Coresh J, Devuyst O, Johnson RJ, Köttgen A, Levey AS, Levin A. Evolving importance of kidney disease: from subspecialty to global health burden. Lancet 2013;382:158-169. Epub 2013 May 31

15. Wühl $E$, van Stralen KJ, Verrina $E$, Bjerre $A$, Wanner C, Heaf JG, Zurriaga O, Hoitsma A, Niaudet P, Palsson $R$, Ravani $P$, Jager KJ, Schaefer F. Timing and outcome of renal replacement therapy in patients with congenital malformations of the kidney and urinary tract. Clin J Am Soc Nephrol 2013;8:67-74. Epub 2012 Oct 18

16. ESCAPE Trial Group, Wühl E, Trivelli A, Picca $S$, Litwin $M$, Peco-Antic A, Zurowska A, Testa S, Jankauskiene A,Emre 
S, Caldas-Afonso A, Anarat A, Niaudet P, Mir S, Bakkaloglu A, Enke B, Montini G, Wingen AM, Sallay P, Jeck N, Berg U, Caliskan S, Wygoda S, Hohbach-Hohenfellner K, Dusek J, Urasinski T, Arbeiter K, Neuhaus T, Gellermann J, Drozdz D, Fischbach M, Möller K, Wigger M, Peruzzi L, Mehls O, Schaefer F. Strict blood-pressure control and progression of renal failure in children. N Engl J Med 2009;361:1639-1650.

17. van Stralen KJ, Borzych-Ducalka D, Hataya $H$, Kennedy SE, Jager KJ, Verrina E, Inward C, Rönnholm K, Vondrak $K$, Warady BA, Zurowska AM, Schaefer F, Cochat P; ESPN/ERAEDTA registry; IPPN registry; ANZDATA registry; Japanese RRT registry. Survival and clinical outcomes of children starting renal replacement therapy in the neonatal period Kidney Int 2014;86:168-174. Epub 2014 Feb 5

18. Querfeld $U$, Anarat $A$, Bayazit AK, Bakkaloglu AS, Bilginer Y, Caliskan S, Civilibal M, Doyon A, Duzova A, Kracht D, Litwin M, Melk A, Mir S, Sözeri B, Shroff R, Zeller R, Wühl E, Schaefer F; 4C Study Group. The Cardiovascular Comorbidity in Children with Chronic Kidney Disease (4C) study: objectives, design, and methodology. Clin J Am Soc Nephrol 2010;5:1642-1648. Epub 2010 Jun 24

19. Hoy WE, Ingelfinger JR, Hallan S, Hughson MD, Mott SA, Bertram JF. The early development of the kidney and implications for future health. J Dev Orig Health Dis 2010;1:216-233.

20. Flynn JT, Ng DK, Chan GJ, Samuels J, Furth S, Warady B, Greenbaum LA; Chronic Kidney Disease inChildren Study. The effect of abnormal birth history on ambulatory blood pressure and disease progression in children with chronic kidney disease. J Pediatr 2014;165:154-162. Epub 2014 Mar 31

21. Rodríguez MM, Gómez AH, Abitbol CL, Chandar JJ, Duara $\mathrm{S}$, Zilleruelo GE. Histomorphometric analysis of postnatal glomerulogenesis in extremely preterm infants. Pediatr Dev Pathol 2004;7:17-25.

22. Abitbol CL, Bauer CR, Montané B, Chandar J, Duara $S$, Zilleruelo G. Long-term follow-up of extremely low birth weight infants with neonatal renal failure. Pediatr Nephrol 2003;18:887-893. Epub 2003 Jun 27

23. Hodgin JB, Rasoulpour M, Markowitz GS, D'Agati VD. Very low birth weight is a risk factor for secondary focal segmental glomerulosclerosis. Clin J Am Soc Nephrol 2009;4:71-76. Epub 2008 Nov 19

24. Verhave JC, Wetzels JF, van de Kar NC. Novel aspects of atypical haemolytic uraemic syndrome and the role of eculizumab. Nephrol Dial Transplant 2014;29(Suppl 4) 131-141.
25. Torres VE. Vasopressin receptor antagonists, heart failure, and polycystic kidney disease. Annu Rev Med 2015;66:195210. Epub 2014 Dec 1

26. Jarzembowski T, John E, Panaro F, Heiliczer J, Kraft K, Bogetti D, Testa G, Sankary H, Benedetti E. Impact of non-compliance on outcome after pediatric kidney transplantation: an analysis in racial subgroups. Pediatr Transplant 2004;8:367-371.

27. Watson AR. Non-compliance and transfer from paediatric to adult transplant unit. Pediatr Nephrol 2000;14:469-472.

28. Aujoulat I, Deccache A, Charles AS, Janssen M, Struyf C, Pélicand J, Ciccarelli O, Dobbels F, Reding R. Non-adherence in adolescent transplant recipients: the role of uncertainty in health care providers. Pediatr Transplant 2011;15:148-156. Epub 2010 Dec 27

29. Watson AR, Harden PN, Ferris ME, Kerr PG, Mahan JD, Ramzy MF; International Society of Nephrology; International Pediatric Nephrology Association. Transition from pediatric to adult renal services: a consensus statement by the International Society of Nephrology (ISN) and the International Pediatric Nephrology Association (IPNA). Kidney Int 2011;80:704-707. Epub 2011 Aug 10

30. Watson AR, Harden P, Ferris M, Kerr PG, Mahan J, Ramzy MF. Transition from pediatric to adult renal services: a consensus statement by the International Society of Nephrology (ISN) and the International Pediatric Nephrology Association (IPNA). Pediatr Nephrol 2011;26:1753-1757.

31. Gallieni M, Aiello A, Tucci B, Sala V, Brahmochary Mandal SK, Doneda A, Genovesi S. The burden of hypertension and kidney disease in Northeast India: the Institute for Indian Mother and Child noncommunicable diseases project. Scientific World Journal 2014;2014:320869.

32. White A, Wong W, Sureshkumur P, Singh G. The burden of kidney disease in indigenous children of Australia and New Zealand, epidemiology, antecedent factors and progression to chronic kidney disease. Journal of paediatrics and child health 2010;46:504-509.

33. Zarocostas J. Need to increase focus on non-communicable diseases in global health, says WHO. BMJ 2010;341:7065.

34. Gulland A. WHO agrees to set up body to act on noncommunicable diseases. BMJ 2013;346:3483.

35. Feehally J. Chronic kidney disease: Health burden of kidney disease recognized by UN. Nat Rev Nephrol 2011;8:12-13.

36. Couser WG, Remuzzi G, Mendis S, Tonelli M. The contribution of chronic kidney disease to the global burden of major noncommunicable diseases. Kidney Int 2011;80:1258-1270. Epub 2011 Oct 12 